Pushpakumara, Kotagama, Marambe, Gamage, Silva, Gunaratne, Wijesundara and Karaluvinne. 2002. Sri Lankan Journal of Agricultural Economics. Volume 4. Part 1. Pp. 39-71.

\title{
Prospects of Pharmaceutical Prospecting to Finance Biodiversity Conservation in Sri Lanka
}

\author{
D.K.N.G. Pushpakumara, H.B. Kotagama, B. Marambe, \\ G. Gamage, K.A.I.D. Silva, L.H.P. Gunaratne, \\ C. Wijesundara and S.S.D.K. Karaluvinne ${ }^{*}$
}

\begin{abstract}
Identifying mechanisms to finance environmental conservation is crucial to achieve sustainable development. Pharmaceutical prospecting has been touted as a mechanism with prospects to generate revenue to conserve biodiversity. Pharmaceutical prospecting could improve with the use of prior information to guide pharmaceutical prospecting research. Such prior information could be traditional knowledge on use of biodiversity for medicinal purposes. Sri Lanka is richly bestowed with both biodiversity and traditional knowledge of the use of it for medicinal purposes. This paper, through review of the literature and empirical estimation of the willingness to pay for pharmaceutical prospecting, has estimated the complementary value of biodiversity and traditional knowledge of its use, in Sri Lanka. The Knuckles forest has been used as the demonstrative case for analysis. It is found that pharmaceutical prospecting has reasonable potential to generate revenue to conserve biodiversity in Sri Lanka. Thus, it is recommended that legislations, institutions and mechanisms, which are required to establish property rights on biodiversity and traditional knowledge, be expeditiously established to facilitate pharmaceutical prospecting. Given the social and political sensitivity of pharmaceutical prospecting, broad public consultation should be sought, prior to implementation of pharmaceutical prospecting.
\end{abstract}

The authors are, respectively, Senior Lecturer in Crop Science, Professor of Agricultural Economics, and Senior Lecturer in Crop Science, University of Peradeniya, Director, and Deputy Director, Ministry of Environment and Natural Resources, Senior Lecturer in Agricultural Economics, University of Peradeniya, Director, Royal Botanic Gardens, and Graduate Student, Postgraduate Institute of Agriculture, Sri Lanka. 


\section{Introduction}

Identifying mechanisms to finance environmental conservation is crucial to achieve sustainable development. This is particularly important given the worsening crisis in public financing in Sri Lanka and the declining availability of foreign finance as concessionary loans and grants, with Sri Lanka achieving the status of a 'middle income country'. For financing to be sustainable, it is best, if possible, that environmental conservation is self financed, i.e. finance environmental conservation on revenue generated on, pricing where possible, the use of environmental resources (Kotagama, 2002).

An environmental resource that Sri Lanka has been bestowed with is biodiversity. Given the high biodiversity and its endemecity, Sri Lanka has been identified as a biodiversity 'hot spot' in the world. The total economic value of biodiversity consists of consumptive, non-consumptive, option, bequest and existence values (see Kotagama, 1998 for a review of estimates on value of Sri Lankan biodiversity). Option values of biodiversity could be appropriated through biodiversity prospecting i.e. commercializing the search for chemicals or genetic material useful in pharmaceutical industry, and agricultural and other biotechnological industries.

The scientific community and
the public have touted pharmaceutical prospecting to have a significant potential (i.e. a viable mechanism to generate revenue) to conserve biodiversity. The reason to have such an expectation is related to early studies that reported high revenues generated by 'harvesting and use of medicinal plants' and the continuity of piracy of plant material for pharmaceutical prospecting (biopiracy). The validity of this expectation has been negated by past international (Pearce and Moran, 1994; Simpson et al, 1996) and national (Kotagama, 1996) research that have estimated low prospects of generating revenues from pharmaceutical prospecting (alternatively low willingness to pay by pharmaceutical prospectors to use plants for pharmaceutical prospecting). However, there is a recent resurgence of evidence of improved prospects (i.e. revenue generation) from pharmaceutical prospecting, based on research by Rausser and Small (2000). The potential for pharmaceutical prospecting has been shown to improve with the use of prior information in guiding pharmaceutical prospecting research. Rausser and Small (2000) have considered the density of species of a 
site as an aspect of prior information that could improve the success of pharmaceutical prospecting research. Whilst acknowledging the inadequacy of a single criterion to represent prior information to guide research, they have identified Traditional Knowledge on use of Biodiversity (TKB) as an important aspect of prior information that could guide pharmaceutical research.

The use of TKB as prior information to guide pharmaceutical prospecting research could increase the probability of success of research and thereby increase revenue generation. Conservation and use of biodiversity and TKB are thus complimentary in generating potential revenue. Sri Lanka is bestowed with both high biodiversity and TKB. Therefore, it is hypothesized that the country would be able to generate sufficient revenue through pharmaceutical prospecting to finance forest biodiversity conservation. This study, through a review of the literature and empirical estimation of the Willingness To Pay $(\mathrm{WTP})^{1}$ by the pharmaceutical industry for pharmaceutical prospecting, examines the potential of pharmaceutical prospecting to generate revenue to conserve forest biodiversity in Sri Lanka.

Upon briefly stating the objectives and hypothesis of the paper, the conceptual model that guide the analysis is presented. The model presumes that a major reason for loss of forest biodiversity is encroachment of forests for agricultural purposes. Therefore, if pharmaceutical prospecting could generate revenue larger than revenue from agricultural land use, forest encroachment could be prevented. Next, literature on estimation of WTP for pharmaceutical prospecting and the implication of past estimates of WTP on conservation of forest biodiversity is discussed. The subsequent section presents the results of the empirical estimate of the WTP for pharmaceutical prospecting in the Knuckles forest in Sri Lanka. Finally, limitations of pharmaceutical prospecting for being a viable mechanism to finance forest biodiversity conservation is discussed, leading to a brief conclusion giving recommendations for future policy and strategy.

Alternatively referred to as revenue generating potential, value and benefit of pharmaceutical prospecting. 
Objective of the Paper

The objective of this paper is to examine the potential of pharmaceutical prospecting to finance the conservation of forest biodiversity in Sri Lanka. The paper is based on a review of the literature and an empirical case study on the Knuckles forest in Sri Lanka.

The specific objectives of the paper are as follows:

i. Review literature on estimates of WTP for pharmaceutical prospecting.

ii. Estimate the WTP for pharmaceutical prospecting of the Knuckles forest in Sri Lanka, recognizing the complimentary link between biodiversity and TKB in improving the WTP.

iii. Based on (i) and (ii) above, examine whether potential revenue from pharmaceutical prospecting could finance forest biodiversity conservation in Sri Lanka.

\section{Hypothesis of the Paper}

A major cause of loss of forest biodiversity is the encroachment of forestland for agricultural purposes by villagers in the peripheries of forests (VPF). Thus, if pharmaceutical prospecting is to, on its own, finance forest biodiversity conservation, a minimum requirement is that the revenue received by pharmaceutical prospecting must be larger than revenues generated from agricultural land use, such that VPF could be compensated to refrain from encroaching forests. Hence it is hypothesized that the WTP for pharmaceutical prospecting could generate revenue higher than agricultural land use.

\section{The Conceptual Model}

The conceptual model is based on the basic economic principle of opportunity cost based decisionmaking. It is presumed that a major cause of loss of forest biodiversity is due to encroachment of forestland for livelihood purposes (particularly agricultural) by VPF. This is because revenue (monetary or otherwise) from agricultural land use is larger than forestland use. Therefore if forests are to be conserved, revenue from forestland use must be made larger than agricultural land use.

It is believed that the pharmaceutical industry earns extremely high revenue on using 'chemical leads' derived from biodiversity, in producing and selling pharmaceuticals. Sharing of this revenue equitably, with those who contribute to conserve biodiversity, would be an incentive for 
biodiversity conservation. Among those who contribute to conserve biodiversity are VPF, by bearing the opportunity cost of not clearing forestland to generate revenue from agriculture. A share of revenue of pharmaceutical prospecting, if received by VPF that is larger than revenue derived from agricultural land uses, VPF would be weaned away from encroaching into forestland, resulting in the conservation of biodiversity (Thushantha and Kotagama, 1995; Kotagama 1996; Barrett and Lybbert, 2000).

The validity of this belief primarily depends on the magnitude of revenue that could be generated through pharmaceutical prospecting and the potential to share the revenue among those who contribute to generate the revenue. The magnitude of the revenue that could be generated depends on the WTP for pharmaceutical prospecting by the pharmaceutical industry. Estimates done since the 1980's on the WTP for pharmaceutical prospecting has ranged between 'very high' and 'very low', creating optimism and pessimism on potential for pharmaceutical prospecting to finance environmental conservation. The reasons for the wide range in the estimates of WTP for pharmaceutical prospecting are ascribed to the differences in the methods and scope of estimation. As revealed in section 5 , estimates of total value of biological resources used for medicinal purposes have estimated high values. Estimates of average option values of pharmaceutical prospecting of sites have estimated moderate values. Estimates of the marginal value of species/sites have estimated very low values. Finally estimates of marginal values of sites that recognize the complementary link between biodiversity and use of prior information (site quality, prior research, TKB etc.) in pharmaceutical research, have estimated very high values.

It has been estimated that the WTP for prior information could be higher than the scarcity value of biodiversity in pharmaceutical prospecting (Rausser and Small, 2000). Kotagama (1996) upon estimating the WTP for pharmaceutical prospecting of Sinharaja forest in Sri Lanka, recommended that TKB be conserved and used to increase the probability of success of pharmaceutical research to derive higher WTP, for Sri Lankan biodiversity.

Conceptually, TKB would increase the probability of success of pharmaceutical prospecting research, which in turn would increase WTP and finally the potential to generate 
higher revenue from pharmaceutical prospecting. Hence, it is necessary to establish the contribution that TKB could increase the probability of success of pharmaceutical prospecting research to estimate the contribution of TKB to the revenue generating potential of pharmaceutical prospecting. Given the lack of empirical information on such, this study estimates the sensitivity of WTP for pharmaceutical prospecting on change in probability of success of research, based on indicative probabilities. This study is a revision of an earlier study by Kotagama (1996) to examine whether pharmaceutical prospecting could generate sufficient finance to conserve forest biodiversity, given the complimentary link between biodiversity and TKB in improving WTP for pharmaceutical prospecting.

\section{Review of Literature}

The Prospect of pharmaceutical prospecting to finance forest biodiversity conservation depends primarily on two aspects, namely i. the magnitude of the potential revenue that can be generated by pharmaceutical prospecting (which depends on WTP) and

ii. the potential to distribute the revenue among those who contribute to generate the revenue (which include VPF).

This review is focused on the potential revenue that could be generated from pharmaceutical prospecting only. The issue of distribution of revenue among those who contribute to generate the revenue is addressed in Pushpakumara et al., (2002). The opportunity cost of land under forest biodiversity conservation is considered as the forgone revenue from cultivation of tea ${ }^{2}$. According to the Central Bank of Sri Lanka (2000) the profit from tea cultivation is Rs. 42,068 /ha/yr (US\$ $554 / \mathrm{ha} / \mathrm{yr}){ }^{3}$

As mentioned earlier, the estimates on WTP and thereby potential revenue that can be generated from pharmaceutical prospecting has ranged from very low to very high, depending on the approach of valuation. Studies that influenced interest on pharmaceutical

$2 \quad$ Tea cultivation is a major cause of forest encroachment in the wet zone of Sri Lanka. Subsistence agriculture, though responsible on a large scale for forest encroachment, yields less revenue than tea. Hence revenue from tea is an upper bound value of opportunity cost of forest conservation. The exchange rate used in this study is 1 US\$ = Sri Lankan Rs. 76 (Central Bank, 2000). All numbers are rounded up to non-decimals. 
prospecting could be categorized to four as listed below and are reviewed next.

i. Valuation of total use value of biodiversity as medicines.

ii. Valuation of average option use value of biodiversity in pharmaceutical prospecting.

iii. Valuation of the WTP for the option value of the marginal species in pharmaceutical prospecting without use of prior information in the research process.

iv. Valuation of the WTP for option value of the marginal site in pharmaceutical prospecting with use of prior information in the research process.

\section{Valuation of total use value of biodiversity as medicines}

The earliest studies have estimated the revenue generated from direct use of plants for medicinal purposes or revenue generated from sale of pharmaceuticals produced from chemicals derived from plants. As reported by Anon (2002) quoting Pearce and Puroshothamon (1995), pharmaceuticals have an annual sales value exceeding US\$ 200 billion and over $25 \%$ of the drugs sold in the developed countries and $75 \%$ in the developing countries are based on chemicals made by organisms. The value per untested species in pharmaceutical prospecting as estimated by Principe (1989) and Aylward et al. (1993) and reported by Barrett and Lybbert (2000) range from US\$ 23.7 and US\$ 44.0 million (Rs. 1,801 million to Rs. 3,344. million). ${ }^{4}$ This estimate is based on the product value of the plant based pharmaceuticals and the probability of success of pharmaceutical research. A study by Balick and Mendelsohn (1992) as reported by Anon (2002) has estimated that revenues ranging from US\$ 16 to US\$ 61 ha/yr (Rs. 1,216 to Rs. 4,636 /ha/yr) could be earned by harvesting medicinal plants from rainforests.

Gunatilake (1991) and Gunatilake et al. (1993) estimated that VPF of the Sinharaja and Knuckles forests in Sri Lanka earned US\$ 13 /ha/yr (Rs. $988 / \mathrm{ha} / \mathrm{yr}$ ) and US\$ 54 /ha/yr (Rs. 4,095/ha/yr) respectively, from collecting nontimber forest products (of which medicinal plants is one). Bogahawatte (1999) has estimated a cash income of Rs. 67 /yr/household

$4 \quad$ Values reported in earlier studies have not been standardized to reflect current values. The values are those reported in the original source. 
(US\$ 0.88 /yr/household) obtained by VPF in the wet zone of Sri Lanka by harvesting medicinal plants.

Valuation of option use value of biodiversity in pharmaceutical prospecting

Pearce and Moran (1994) have estimated option value of pharmaceutical prospecting to be in the range from US\$ 0.01 to US\$ $21.00 / \mathrm{ha} / \mathrm{yr}$ (Rs. 0.76 to Rs. 1,596 $/ \mathrm{ha} / \mathrm{yr}$ ). They considered the potential revenue that could be generated from pharmaceutical prospecting of plants as a function of number of plant species at risk of extinction, extent of land having plants that would be of interest to pharmaceutical prospecting, value per drug produced and marketed plant based chemicals (or value of life saved by use of plant based drugs), probability of success of pharmaceutical research, royalty rate, and appropriation rates in estimating the potential revenue that can be generated from a hectare of land in pharmaceutical prospecting. The range is based on sensitivity analysis on the highest and lowest values of variables identified above.

Thushantha and Kotagama (1995), and Kotagama (1996), using the method that was proposed by
Pearce and Moran (1994), estimated the option value that can be generated from pharmaceutical prospecting of Sinharaja forest of Sri Lanka as US\$ 77.00 /ha/yr (Rs. 5,900 /ha/yr). A study by Karaluvinne (2001) using the same methodology estimated the option value that can be generated from pharmaceutical prospecting of Knuckles forest of Sri Lanka as US\$ $19.67 / \mathrm{ha} / \mathrm{yr}$ (Rs. 1,495/ha/yr). These studies considered only information on woody plants in the estimation of option value. All the studies compared the revenue generating potential of pharmaceutical prospecting with agricultural land use by VPF and found that potential revenues from pharmaceutical prospecting was lower than agricultural land uses. Thus, these studies concluded that pharmaceutical prospecting, on its own, would not be able to generate finances to conserve forest biodiversity. These studies, through sensitivity analysis on variables such as the royalty rate, appropriation rate and the degree of success of research, highlighted the need to strengthen property rights on biodiversity and TKB. 
Valuation of the WTP for the option value of the marginal species in pharmaceutical prospecting without use of prior information in the research process

Simpson et al. (1996) questioned the validity of estimates of total and average value of pharmaceutical prospecting in economic decisionmaking, as it is the marginal values that are relevant in economic decision-making Simpson et al. (1996) estimated the marginal value (WTP) of species and extended it to per hectare value in pharmaceutical prospecting. The maximum WTP (at $10 \%$ discount factor and time ranging from present to infinity) for pharmaceutical prospecting of forest in the southwestern Sri Lanka has been estimated as US\$ 16.84 /ha (Rs. 1,263 /ha). The highest value estimated was US\$ 20.63 /ha for Western Ecuador. It was concluded that the value of pharmaceutical prospecting being 'vanishingly small' could not provide an incentive for conservation. This is true, compared to profitability of tea cultivation in Sri Lanka, which is
Rs. 42,068 /ha/yr. Estimation of Simpson et al. (1996) was based on a pharmaceutical research process that randomly picked species for research, considering all species as having equal potential in pharmaceutical prospecting. Thereby the research process does not use prior knowledge to guide research. ${ }^{5}$ A subsequent study by Simpson and Sedjo (1996) has further shown that the marginal value of a hectare of land on biodiversity prospecting would remain to be very small, even if increased investments are made on biotechnological advances to reduce the time of researching. ${ }^{6}$

\section{Valuation of WTP for the option value of marginal site in pharmaceutical prospecting with use of prior information in the research process.}

Rausser and Small (2000) critiqued that the estimate of Simpson et al (1996) as not having considered the possibility of using prior knowledge to guide pharmaceutical prospecting research.

$5 \quad$ However, Simpson and Sedjo (1996) admit these shortcomings in their work and claim that even if these shortcomings are rectified, it would not make a difference to the conclusion that the value of the marginal species of biodiversity in pharmaceutical prospecting in very small.

6 Advances in biotechnology, however, could reduce the time of researching and also contribute to increase the probability of success of research at a given point in time. 
They considered that a sequential search with prior knowledge on the biodiversity of sites could increase the probability of success and also decrease the cost of research. They also alleged that Simpson et al's (1996) estimate of the value of the marginal species as pragmatically meaningless, as decisions on biodiversity prospecting would be based on sites ${ }^{7}$. Rausser and Small (2000) considering 18 sites (the same as those considered by Simpson et al., 1996) and using the information on the density of endemic species as prior information, estimated the present value of WTP of pharmaceutical prospecting. ${ }^{8}$ The estimated WTP for pharmaceutical prospecting for forest in southwestern Sri Lanka is US\$ 7,463 /ha (Rs. $567,188 / h a)$, which is the world's second highest among the estimates. The highest WTP (US\$ 9,177/ha) is for western Ecuador and the third highest present value (US\$ $5,473 / \mathrm{ha}$ ) is for New Caledonia. The lowest non-zero value reported is
US\$ 231 /ha for Central Chile (Rausser and Small, 2000).

Both estimates, by Simpson et al. (1996) and Rausser and Small (2000), for southwestern Sri Lanka were based on the following information: forest area in south western Sri Lanka as 70,000 hectares, density of endemic species per 1000 hectares in forests in south western Sri Lanka as 7.14, the probability of success of pharmaceutical prospecting research as 0.000012 , probability that a research project would not yield success as 0.63 , value of a successful pharmaceutical discovery as US\$ $450,000,000$, cost per test as US\$ 485 , an interest rate of $10 \%$, and projects launched at a rate of 26 per year. Despite using the same information, except the consideration of the use of prior information (density of endemic species in a site) in pharmaceutical prospecting research and a sequential research

$\overline{7} \quad$ Although Simpson et al. (1996) estimate the marginal value of a species in pharmaceutical prospecting, it is extended to the marginal value of hectare of land,. Further, although contracting of pharmaceutical prospecting deals would be done pragmatically by site or land extent, species could also be the unit of contract considering the widely alleged practice of piracy of species (biopiracy) for pharmaceutical prospecting and other purposes. The American Agricultural Economics Association has acknowledged the theoretical and methodological rigor of this paper by awarding the Quality of Research Discovery Award (www.columbia.edu). 
process (over a random research process), the estimate of Rausser and Small (2000) varies by a magnitude of 443 times over that of Simpson et al. (1996). ${ }^{9} \quad$ The higher value estimated by Rausser and Small (2000) is attributed to information rent, in this case density of endemic species. If additional information of TKB were considered the value would have increased further.

If WTP estimated by Rausser and Small (2000) of US\$ 7,463 /ha is spread over 10 years at a $10 \%$ interest rate the value is US\$ 1,214 ha/yr (Rs. 92,264 /ha/yr) and if spread over 100 years it is US\$ 746 /ha/yr (Rs. 56,696 /ha/yr). A major commercial crop cultivated in the southern area of Sri Lanka and is encroaching forests is tea. In year 2000 the profit from tea cultivation has been Rs. 42,068 /ha/yr (Central Bank of Sri Lanka, 2000). Hence, it is clear that pharmaceutical prospecting could generate revenues, significantly more (1.3 times) than tea cultivation even on a time span of 100 years. However, the transaction cost of institutionalizing pharmaceutical prospecting has not been included in the opportunity cost. As the potential transactions costs are not known, an upper bound value of the revealed costs incurred by the whole of the Ministry of Forestry and Environment in year 2000 in managing forest in Sri Lanka was considered as a proxy. ${ }^{10}$ The recurrent and capital expenditure of the Ministry of Forestry and Environment during year 2000 has been Rs. 250 million and Rs. 608 million (US\$ 3.3 million and US\$ 8.1 million) (Central Bank of Sri Lanka, 2000). The extent of forest area managed by the Sri Lankan Forest Department is $1,150,533$ ha (www.fao.org). If all the expenditure under the Ministry of Environment and Forestry were allocated to the Forest Department, then the forest resource administrative cost would be Rs. $746 / \mathrm{ha} / \mathrm{yr}$. If this cost is added to the opportunity cost of

B $\quad$ Both estimates were published in the Journal of Political Economy within a time span of 4 years. This vast divergence of estimates has serious implications on the use of economic estimates to guide policy. Policy decision makers may tend to doubt economic estimates of value. This however does not negate the validity of the scientific research process of refutation based on improved information.

This is an overestimate due to two reasons. First the organizations to which money is allocated by the Ministry of Forestry and Environment are several other than the Forest Department. Second if transaction costs of pharmaceutical prospecting is to be undertaken by the Forest Department it would only be incremental to the existing costs of the Department. 
land under forests in Sri Lanka, it is Rs. 42,814/ha/yr. Given the WTP for pharmaceutical prospecting as Rs. 56,696 /ha/yr as estimated by Rausser and Small (2000), it is not only possible to compensate the VPF not to encroach forests but also finance the recurrent and capital budget of the Ministry of Environment and Forestry for the next 100 years.

Further, considering a time span of 100 years and the WTP for pharmaceutical prospecting, the total value that the southwestern region could obtain is 70,000 ha $\mathrm{x}$ US\$ 746 /ha/yr = US\$ 52,220,000 /yr (Rs. 397 million/yr). This could be compared with revealed expenditures on forest biodiversity conservation in the whole of Sri Lanka. The World Bank project on Conservation of Medicinal Plants has spent only Rs. 2 million in year 2000, and the Asian Development Bank funded Participatory Forestry Project in Sri Lanka has spent only Rs. 33.4 million in year 2000. It is clear that the revealed expenditures, particularly by the international community as abysmally small compared to the WTP. ${ }^{11}$ Whilst Simpson et al.'s (1996) estimate of
WTP for pharmaceutical prospecting is "vanishingly small" and the estimate by Rausser and Small (2000) is "visibly big" compared to revealed expenditure, Sri Lanka could benefit substantially by way of appropriating the WTP for pharmaceutical prospecting based on Rausser and Small's (2000) "visibly big" estimate. However, there is neither yet any recorded information that Sri Lanka has reacted to this prospect nor that those who are WTP have approached Sri Lanka for pharmaceutical prospecting. Simpson (1995) in observing the overenthusiasm shown by the public on pharmaceutical prospecting despite the low estimated WTP for pharmaceutical prospecting noted that:

"If observation is at variance with economic logic, it would hardly be the first time."

This may now be rephrased in relation to Rausser and Small's (2000) estimate of WTP for pharmaceutical prospecting as:

"If observation is at variance with economic logic, it would hardly be the second time."

11. The alleged continuation of bio-piracy and the offer of a "nature for debt swap" on Sri Lankan forests by the United States of America may also be indicators of revealed behavior based on the high value of Sri Lankan biodiversity. 
Rausser and Small (1998) in an article on 'bio-prospecting with patent races' claim that:

“... when the buyers of genetic resources options are also competitors in patent races, sellers can extract all the surplus associated with their holdings. Under reasonable conditions, the ex ante return to genetic resources assets will then be determined, not by their marginal contribution to surplus, but by their average contribution. The result implies that several bio-economic studies reporting large average species values provide credible estimates of the strength of market incentives for biodiversity conservation."

In reviewing the past estimates of pharmaceutical prospecting it is observed that the WTP values range from "pennies in the lower end, US\$ $21 /$ ha in the mid to US $\$ 9,000 /$ ha in the higher end. Based on the most recent estimates that are "visibly big" it is clear that pharmaceutical prospecting alone could finance the conservation of forest biodiversity. However, Barret and Lybbert (2000) suggested that whether pharmaceutical prospecting could generate revenue to conserve biodiversity conservation by tipping the benefit cost scales on land use in favor of conservation is a context specific, empirical question. It also found that estimates of average values of pharmaceutical prospecting are credible estimates (Rausser and Small, 1998).

\section{Analytical Method}

An objective of this study is to empirically estimate the WTP (therefore potential revenue that could be generated) for pharmaceutical prospecting of Knuckles forest in Sri Lanka. Pearce and Moran's (1994) method of estimation of the average revenue that could be generated by pharmaceutical prospecting is used in this study. The complementary relationship between biodiversity and $\mathrm{TKB}$, in generating higher revenue from pharmaceutical prospecting is specifically recognized. Pearce and Moran's (1994) method is used due to its simplicity of the estimation procedure and due to explicit inclusion of policy variables that could be subjected to sensitivity analysis. The primary focus is on examining the sensitivity of WTP on the probability of success of research, which could be influenced by use of TKB.

The Pearce and Moran's (1994) method estimates the potential average revenue per hectare per annum that could be generated from 
pharmaceutical prospecting using the relationship given in the following equation,

$V_{m p}(L)=\left\{N R^{*} \cdot p^{*} \cdot r^{*} \cdot a^{*} \cdot V_{i} / n\right\} / A$

where: $\mathrm{V}_{\mathrm{mp}}(\mathrm{L})$ is potential revenue that could be generated from pharmaceutical prospecting per hectare per year, NR is number of plant species at risk of extinction, $\mathrm{P}$ is the probability of discovering a drug from a plant, $r$ is the royalty rate on pharmaceutical prospecting, a is the probability of appropriating revenue generated from pharmaceutical prospecting, $V_{i}$ is the value of a plant based drugs per year (where i could be based on estimates such as the market value of drugs derived from plant based chemicals or the value of lives saved by use of drugs derived form plant based chemicals), $\mathrm{n}$ is the number of plants that had been used in developing drugs and $\mathrm{A}$ is extent of land under biodiversity conservation. The measurement of these variables is explained below.

\section{Number of plant species at risk of extinction (NR)}

The NR is a proxy measure of economic scarcity of plants. Pearce and Moran (1994) used the number of species that 'would be extinct' (endangered) in the next 50 years as
NR (60,000 species). Although this measure is appropriate to measure scarcity of biodiversity at a global level, it is not sufficiently accurate to measure scarcity of biodiversity at a country or site level. If a species is found in more than one country, pharmaceutical prospectors could move from one country to another given the substitutability. In order to recognize the drop in scarcity value due to substitutability between countries, only endemic and endangered species should be considered in a country or site. Endemics indicate scarcity over space, whilst endangeredness indicates scarcity overtime of species. The scarcity imposed over time of species was not considered in this study due to lack of information on how many of the endemics are endangered and vice-versa. This study used the identified number of endemic woody plants as the scarcity indicator of plants in the Knuckles forest area, which is 85 (see Table 1). Since only endemics have been considered in the study estimates are skewed to the upper bound.

\section{Probability of success of inventing a plant based drug (p)}

Pearce and Moran (1994) have reported (quoting Principe, 1991) that the probability of success of inventing a drug ranges from 0.001 to 0.0001 , as revealed by experts 
Table 1: $\quad$ Diversity of woody plant species within the Knuckles forest

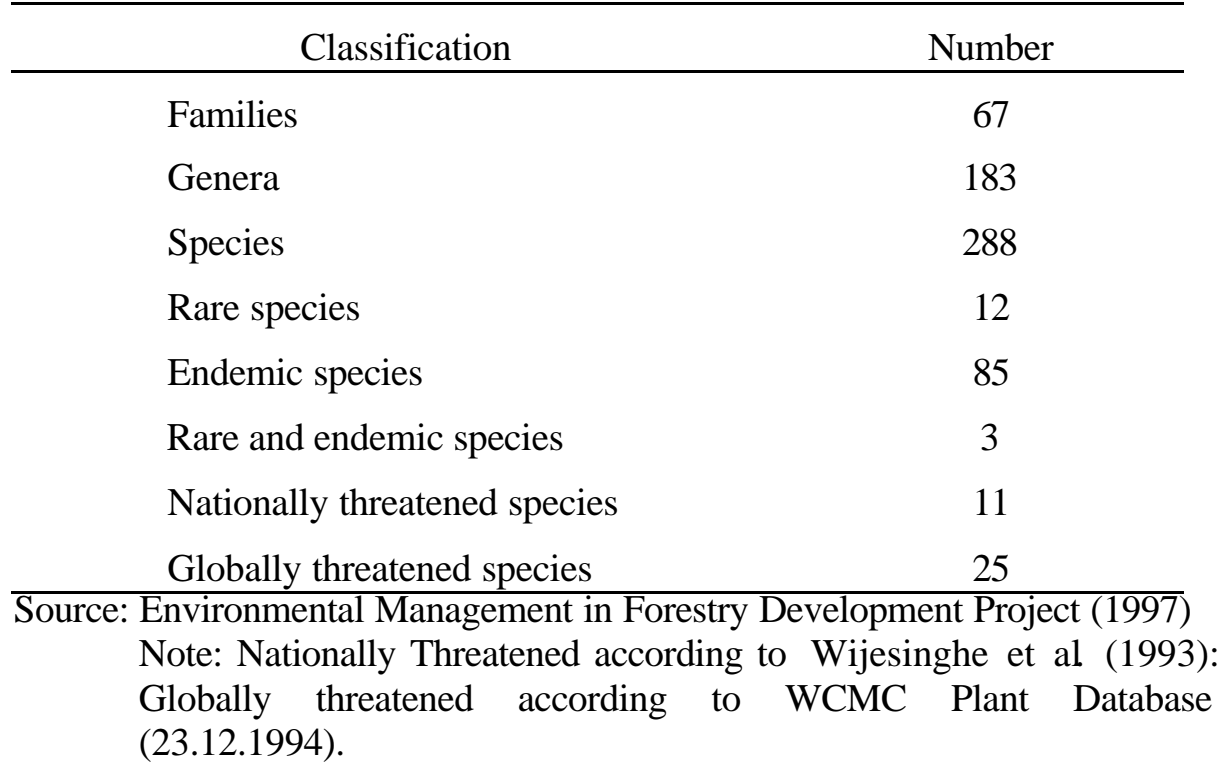

of pharmaceutical companies. As reported by Anon (2002), during 1986 to 1995 the National Cancer Institute of United States, using improved screening methods, had produced 40,000 plant extracts for screening and of the 18,000 screened for anticancer activity about $0.01 \mathrm{had}$ showed some positive activity.

The increase in pharmaceutical prospecting values does not have a straight-line relationship with probability of success of research. Simpson (1995) explains this relationship as follows.

"If it is relatively likely that any species chosen at random will yield the product you seek, it is also highly probable that two or more species will. Your incentives to maintain large expanses of unspoiled habitat will be low. Conversely, suppose that the probability with which any species chosen at random will yield the commercial product you seek is low. It is now unlikely that two or more species will prove to be redundant, but it is also unlikely that you'll find any species that meets your need."

Hence, neither very low nor very high probability of success of research would generate incentives for conservation of biodiversity. Simpson et al., (1996) have 
estimated the probability of success that could give the highest value of the marginal species as 0.000012 . This is true in a global sense. For a particular site it may be reasonable to assume that probability of success of research and pharmaceutical prospecting values are linearly related.

Probability of success of pharmaceutical prospecting research, as with the case of any research, will improve with use of prior information and has been empirically proven by Rausser and Small (2000) in the case of pharmaceutical prospecting. However, the identification of what consists of prior information and quantification of those and finally establishing a relationship between prior information and probability of success of research is pragmatically difficult due to lack of data. Among the many aspects of prior information such as species density of a site (used by Raussser and Small, 2000), TKB for medicinal purposes could be considered as prior information that could improve the probability of success of pharmaceutical prospecting research. As reported by Kumar (2000) this has been the practice followed by foreign and local scientists in scientific investigation on plants for pharmaceutical prospecting etc, in Sri Lanka. ${ }^{12}$

As much as possessing high biodiversity, Sri Lanka possesess a high base of TKB for medicinal purposes, given its long history. About $35 \%$ of the Sri Lankan population, even at present depends on traditional systems of medical care. About 250 species of medicinal plants are commonly used in traditional medicine of which 50 species are heavily used (http://www.lanka.net/iucnsl). At least 189 of the 1,414 medicinal plants used in Sri Lanka are specific to the island or geographically restricted to the Indian subcontinent, including 79 that are threatened with extinction. Having recognized the importance of TKB for medicines in Sri Lanka, the World Bank (1997) financed, to quote "project first of its kind for World Bank" for the conservation of medicinal plants in Sri Lanka. An activity of the project is to systematically collect traditional knowledge on use of plants for medicinal purposes such that financial rewards are provided to those communities in case of pharmaceutical discoveries. However, if such rewards are to be Chemistry, University of Peradeniya, Sri Lanka. 
provided at least indications of the revenues that could be generated from use of TKB should be known. ${ }^{13}$

Since accurate quantification of the possibility of TKB to improve the probability of success of pharmaceutical research is difficult, proxies could be considered. In Sri Lanka there are 7,456 plant species of which 3,360 flowering plants have been identified (Jayasekera, 1997, quoted in http://www.msssrf.org), and 1,414 plant species are used for medicinal purposes (of which 250 are commonly used and 50 heavily used) thus indicating the very high availability of TKB for medicinal purposes. Hence, to the base of the number of flowering plants identified, 0.42 of the plants are used for medicinal purposes and 0.07 commonly used and 0.01 heavily used. These figures are an indication of the probability of success of traditional knowledge in using plants for medicinal purposes. Further there is documentary evidence of at least two Sri Lankan plants (Salacia reticulata and Salacia prinoides) being patented as having pharmaceutical potential in producing anti-diabetic drugs (Kumar, 2000). Salacia reticulata (referred to as Kothala himbutu in Sri
Lanka) has been traditionally used as an anti-diabetic medicine. If the search process had used traditional knowledge, then the search would have been 2 among at least the 250 plants that are commonly used for medicinal purposes, giving a probability of 0.008 . This study has used (see Table 2) this high probability of success rates on pharmaceutical research, compared to internationally quoted low rates, ascribing such to high availability of $\mathrm{TKB}$, in estimating the revenue that could be generated from biodiversity prospecting in Sri Lanka.

\section{The royalty rate $(\mathbf{r})$}

The royalty rate is the potential payment to the patentee (owner) of biodiversity or traditional knowledge. It could be a nation, institution or an individual depending on the manner of definition of property rights on biodiversity and TKB. Kumar (2000) observes that although Sri Lanka is in the process of legislating property rights on biodiversity and TKB, legislation has not been brought before parliament for approval. Hence, foreign and local scientists have virtually free access to biodiversity and traditional knowledge of its use.

13 A possibility is to use the estimation procedure suggested by Rausser and Small (2000) to estimate information rent of pharmaceutical prospecting. 
Vogel (1996) has suggested that the royalty rate for pharmaceutical prospecting ought to be as high as 0.15 , as with intellectual property with monopoly control. It is suggested that this royalty be shared between the country supplying the sample (1-3\%) and the other countries having the same species the balance (14-12\%). This implies that if a plant is endemic the suggested royalty rate of 0.15 could accrue to one country. However, given the absence of multilateral accord to fix the royalty, it is expected that the royalty would be meager, given the emerging price war among supplying countries. In effect, Vogel (1996) notes that the royalty could drop down as low as 0.02. Hence, Vogel (1996) has recommended that biodiversity supply cartels be institutionalized among supply countries.

In practice, it is reported that Monsanto Company has negotiated bio-prospecting contracts with International Cooperative Biodiversity Group for access to samples with royalties as low as 0.02 on net sales. Pearce and Moran (1994) have used a royalty rate of 0.05 based on the observation that existing royalty rates in general range between 0.05 to 0.20 and that a low figure is applicable for pharmaceutical prospecting. This study has used a royalty rate of 0.05 for the base analysis and has used 0.15 for the sensitivity analysis as only endemic species have been considered for pharmaceutical prospecting.

\section{The probability of appropriating pharmaceutical prospecting values (a)}

This factor quantifies the institutional capability to appropriate the value of research discoveries by the "owners" of biodiversity and TKB. The magnitude of the factor depends on the availability and enforceability of property rights on biodiversity and TKB. As Kumar (2000) observes of Sri Lanka:

"Agreements on benefit sharing are the exception rather than the rule and rarely do developing countries receive any sharing of the benefit from commercial exploitation. A recent example is a Sri Lankan plant, Salacia reticulata, long reputed and locally exploited for its antidiabetic properties. The plant and a related plant found in Sri Lanka, Salacia prinoides, have been investigated in Japan and the United States for this activity and its hypoglycemic constituents have been the subject of several publications (Yoshikawa et al., 1998a, 1998b, 1998c; Shimodo et al., 1998) and 
patents by Japanese (Yamahara, 1999) and American (Inman and Reed, 1997) scientists, with no reference to Sri Lankan participation. It is unlikely that any commercial exploitation of this discovery will result in the sharing of benefits with Sri Lanka or the holders of the traditional knowledge involved."

However, recently Gunawardena (2002) has reported of success of 'establishing the ownership' of Salacia reticulata by banning the export of the plant material from Sri Lanka, thereby making the patent for it virtually ineffective.

Pearce and Moran quoting Ruitenbeek (1989) suggest that the appropriation rate could be as low as 0.1 in developing countries. The fact that appropriation rate is low explains why developing nations feel that the benefit of their efforts to conserve biodiversity is captured more by others (Pearce and Moran, 1994). This study has used an appropriation rate of 0.1 and has conducted sensitivity analysis on possible improvements.

\section{Average annual value of plant based drugs $(\mathrm{V})$}

Pearce and Moran (1994) having considered market value of plants traded for medicinal purposes, and market value of drugs of which the source material has been plants, statistical value of life of lives saved using plant based drugs, have suggested the range US\$ 0.39 to US\$ 7.00 billion as the annual value of a plant based drug. These estimates are gross revenue and not net revenue. According to Anon (2002), the development cost of a pharmaceutical drug is more than US\$ 500 million. However, Pearce and Moran (1994) argue that the negligence of costs would not distort the value. The inelastic nature of demand for drugs, thereby the associated high consumer surplus, is not accounted in the market price of drugs. Hence, market price based value is an underestimate of the real value. Further it is noted that it takes about 10 years from the discovery of a potentially valuable chemical until a new pharmaceutical product is ready for sale (Moore, ud), which will also reduce the value of pharmaceutical prospecting. Both effects together would compensate for neglecting the cost of production of drugs. This study has used the average (US\$ 3.7 billion/year) of the range suggested by Pearce and Moran (1994).

\section{The Knuckles Forest}

The empirical analysis of this study is based on information from the Knuckles forest in Sri Lanka. The 
Knuckles forest is geologically a part of the central massif of Sri Lanka. Its location acts as a boundary wall of the wet and dry zones of the island, and has given rise to a wide range of climates from extreme wet on the southwestern slopes to the dry on the eastern slopes. These factors have all combined to create a unique ecosystem within the Knuckles forests with rich diverse fauna and flora (IUCN, 1994). It exhibits a floristically rich vegetation and comprises of four major forest formations namely, (a) lowland dry semi evergreen, (b) mid elevation wet evergreen, (c) mid elevation dry evergreen, and (d) montane wet ever green forests or cloud forests. This forest ecosystem is a 'gene bank' for a number of wild relatives of crop plants, valuable timber species and medicinal plants. But their populations are decreasing due to habitat destruction caused by encroachment for agricultural activities. Cardamom was a major crop that was cultivated in the Knuckles forestlands. Although encroachment for cardamom cultivation has declined due to reduced crop prices and enhanced enforcement of conservation efforts, encroachment still continues.

\section{Analysis}

The result of the analysis is given in Table 2. The estimates by Pearce and Moran (1994) based on global data are provided for purpose of comparison (row 1 and 2). As indicated earlier, the profit generated by tea cultivation is Rs. $42,068 \mathrm{ha} / \mathrm{yr}$ and of subsistence agriculture is much lower. Revenue from tea cultivation is considered as the opportunity cost of forest biodiversity conservation. The base line estimate (row 3) of potential revenue form pharmaceutical prospecting of the Knuckles forest in Sri Lanka is estimated on average values used by Pearce and Moran (1994) on $\mathrm{p}$ and $\mathrm{V} / \mathrm{n}$. It is evident that based on global estimates as well as data specific to Knuckles forest, the revenue generated by pharmaceutical prospecting is far less than revenue from agricultural land use. Column 9, gives the percentage between pharmaceutical prospecting revenue and the agricultural land use revenue.

Row 5 indicates the potential revenue that could have been generated through pharmaceutical 
Table 2:

Estimated potential revenue from pharmaceutical prospecting

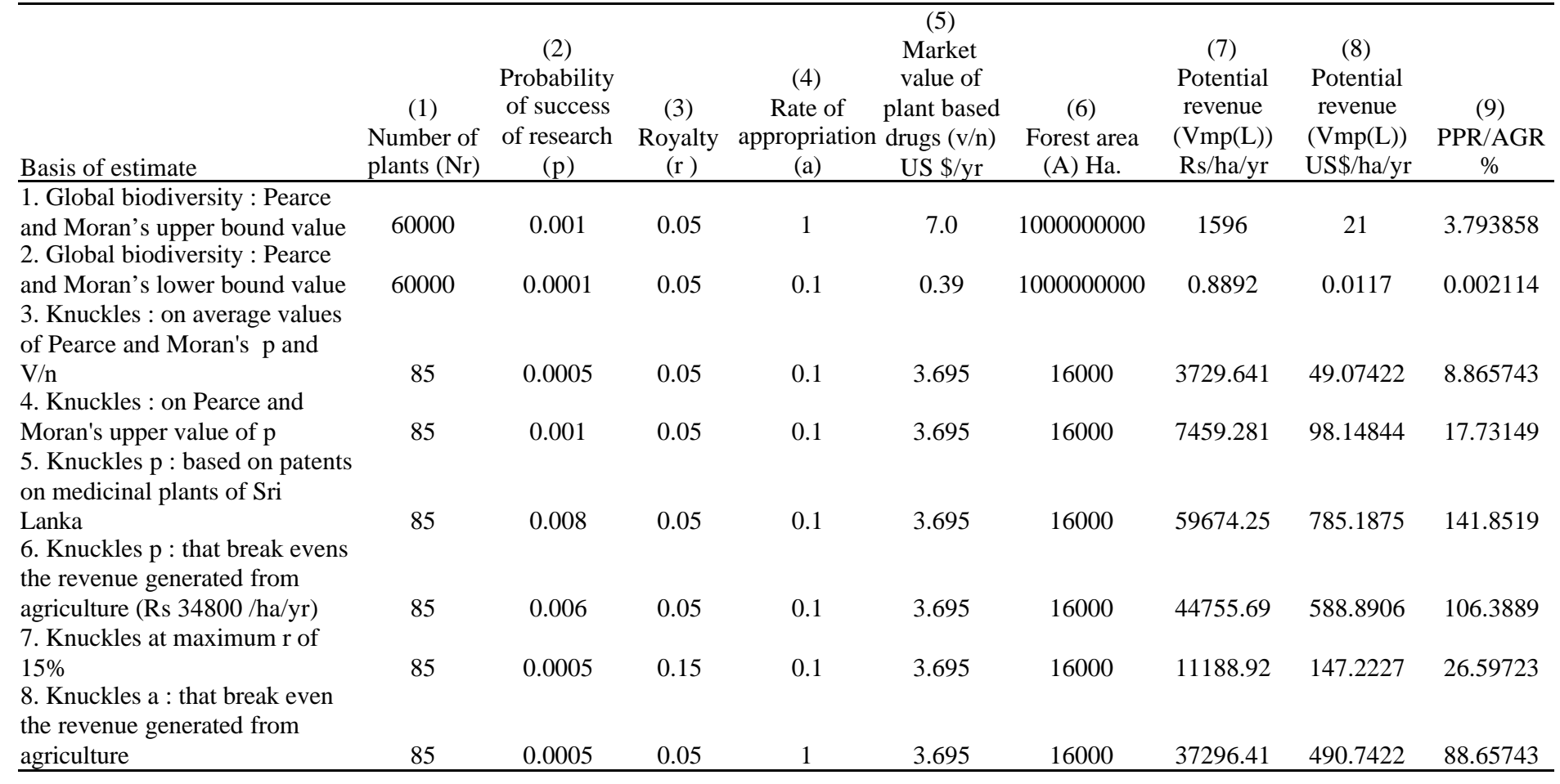


prospecting, based on the recorded fact that 2 Sri Lankan plants have been patented as having potential of producing pharmaceuticals. It is observed that with the probability of success of research as 0.0008 , pharmaceutical prospecting could generate more than the agricultural income $(141 \%)$ in contrast to the base case of $9 \%$. If it is considered that the patent for the two plants was based on research that was guided by use of TKB then it gives an indication of increased revenue that can be generated from use of TKB in pharmaceutical prospecting (Rs. $55,945 / \mathrm{ha} / \mathrm{yr}$ ). Row 6 indicates the probability of success of research required to break even on the revenue generated through agricultural land use, which is 0.006 . If use of TKB of Sri Lanka can improve probability of success of research to 0.006, then pharmaceutical prospecting alone could finance the conservation of biodiversity.

As shown in row 7 , even if the royalty is increased to $15 \%$ (the maximum conceivable on international experiences), the increased revenue would only account to $26 \%$ of the agricultural revenue from land. Further, as shown in row 8 , even if the appropriation rate is $100 \%$ the potential income that could be generated by pharmaceutical prospecting will not be higher than income generated from agricultural land use. Both improving royalty rate and appropriation rate are not very responsive to increasing potential revenue from pharmaceutical prospecting. However, the possibility of increasing the appropriation rate is within the realms of Sri Lanka, whilst the royalty may drop down with international competition and is not controllable by Sri Lanka. Hence, Sri Lanka needs to define and enforce property rights on biodiversity and TKB to earn revenue from pharmaceutical prospecting to finance forest biodiversity conservation.

Based on the above review of literature and indicative empirical analysis, it could be concluded that pharmaceutical prospecting has the potential, even if not fully but at least partially to finance forest biodiversity conservation. A substantial proportion of the opportunity cost of forest biodiversity could be financed through pharmaceutical prospecting.

Given the potential of pharmaceutical prospecting to at least partially finance forest biodiversity conservation, it is necessary that appropriation possibility is improved in Sri Lanka, through enacting legislation on property rights, contracting and trade 
of biodiversity and TKB and the speedy implementation of such with appropriate institutions. Legislation and institutions should encourage legal, formal and commercially oriented pharmaceutical prospecting, early as possible on an internationally competitive basis, such that early benefits are derived.

The increasing value of TKB as a complement to the value of biodiversity in pharmaceutical prospecting should be recognized. It is TKB that is seemingly more scarce and irreversible in loss than biodiversity itself. Appropriate measures to conserve TKB should be taken. As Kumar (2000) suggested, the most pragmatic measure may be formal documentation although it is fraught with difficulties and controversies. The end objective ought to be that TKB is used to generate benefits to Sri Lanka, of which one way is generating finance for forest biodiversity conservation through formal pharmaceutical prospecting. Unless pharmaceutical prospecting is formally undertaken, experience suggest that Sri Lanka gets no benefit due to difficulties of abating bio-piracy.
Although economic analysis shows the potential for Sri Lanka to generate finances to conserve forest biodiversity through pharmaceutical prospecting, the implementation of such will be burdened with difficulties and uncertainties, which are related to socio-political and technological factors. Some of these difficulties and uncertainties are briefly discussed in section 9 .

Further, forest biodiversity is a composite commodity that could generate multiple values other than pharmaceutical prospecting values such as consumptive values of harvest of non-timber products, which directly benefit VPF, nonconsumptive values of eco-tourism, which could be appropriated for the benefit of VPF, watershed benefits to VPF and non-consumptive values as educational values, ecological service values, cultural, existence and spiritual values etc. ${ }^{14}$ Some of these values too, could be appropriated to finance forest biodiversity conservation through appropriate mechanisms. The prospects of particularly eco-tourism should be examined.

\footnotetext{
$\overline{14}$ Benefits from carbon sinks are not considered, because it is unclear whether
} existing forest could receive global payments as carbon sinks. 
Difficulties and uncertainties of pharmaceutical prospecting

The difficulties and uncertainties of implementing pharmaceutical prospecting are discussed as those arising from limitations of economic analysis, socio-political factors that would effect implementation and technological factors that would cause uncertainties on the benefits of pharmaceutical prospecting.

Cause of biodiversity loss: This analysis was based on the premise that the major cause of loss of biodiversity is encroachment of forests by VPF. Biological models too accept this premise that species loss could be related to a smooth function of a habitat conversion (Simpson and Sedjo, 1996; quoting MacArthur and Wilson, 1967). Reardon and Vosti, 1995 (quoted by Barrett and Lybbert, 2000) have empirically proved this premise. Whilst forest encroachment is a major cause of loss of biodiversity in Sri Lanka, historically forests have been cleared on a large scale by colonial and post-colonial governments. There are also indications of selective harvesting of medicinal plants and various nontimber forest products leading to loss of biodiversity (The World Bank, 1997). Such causes of biodiversity loss are not addressed in this study.
Kuznet's relationship: It is widely believed that dependence on forest use by VPF is related to the household income. Whilst poor people depend on forest resources, their dependence may first increase with increasing income and then decrease later as an inverted $U$ curve (referred to as the Kuznet's relationship). Pharmaceutical prospecting, if it succeeds to transfer benefits to VPF, may cause first an increase in the extraction of forest products leading to an accelerated loss of biodiversity, and may even lead to irreversible losses. Although empirical evidence has not been formally reported, an author of this paper observed increased extraction of medicinal plants from an adjacent forest where medicinal plant cultivation and marketing was promoted through a project in Sri Lanka.

Lack of agronomic technology: It could be expected that if a particular plant is found to have potential in producing a drug then there would be a demand for it. Where the technology to grow the plant on a commercial scale is not available it would lead to higher rates of extraction from the wild and that may lead to extinction of the species. Sri Lanka is currently confronted with this problem with Salacia reticulata. 
Distribution of values: Even if the value of pharmaceutical prospecting is substantial, a major factor that would determine the success of pharmaceutical prospecting in financing forest biodiversity conservation is the distribution of the value equitably (alternatively referred to as equitable benefit sharing) to those who contribute to the value addition process of pharmaceutical prospecting. An integral participant in the pharmaceutical prospecting process is the land user in the peripheral area of the forest. If the pharmaceutical prospecting values do not reach them to wean them from encroaching forest, then this process would not provide an incentive to conserve biodiversity in the forest. Some of these issues are reviewed below.

Most discussions on benefit sharing of pharmaceutical prospecting express doubts on the potential for benefit sharing between multinational companies and developing nations that host biodiversity (Kumar, 2000). Multinational companies dominate the global pharmaceutical industry and it is these companies that are often blamed for bio-piracy. This is a contentious issue and will remain to be so. It is often argued that it is beneficial to countries having biodiversity to conduct pharmaceutical prospecting research in their countries and to sell value added products rather than biodiversity and TKB as source material (Kotagama, 1996: Gunawardena, 2002). The potential for such should be researched, as value addition though a benefit involves a cost. The indications are that Sri Lanka does not possess the technology nor could Sri Lanka afford it. The international patent fee itself is US\$ 60,000 (Anon, 1998). However, the decision on whether multinational pharmaceutical industry or national industry undertakes pharmaceutical prospecting would be based on socio-political considerations. This study has objectively shown the potentials of pharmaceutical prospecting irrespective of who undertakes it. On the other hand, national companies too are involved and emerging in the pharmaceutical industry in Sri Lanka, given the growing international demand for natural products in cosmetics and in health treatments. Pushpakumara et al. (2001) have showed that even national companies have not influenced a fair distribution of benefits among those involved in the value addition process in the pharmaceutical industry.

If the revenue of pharmaceutical prospecting were appropriated by the state, then the state would need a mechanism to distribute it, 
particularly to reach the land users in VPF. The common approach has been through implementation of integrated conservation and development projects also referred to as buffer zone development projects. The effectiveness of this approach has been doubted. Given the power structures in rural society, it may happen that, finances spent in the form of investments in buffer zone development may flow to the village elites rather than to the poor who encroach forests. Barrett and Lybbert (2000) mention that the experiences of the last 15 years on integrated conservation and development projects indicate that governments have not been successful in transferring environmental rents to "locals" to achieve conservation objectives.

Transaction costs of negotiation, property rights: The appropriation of pharmaceutical prospecting values, first by state and then to transfer to the villagers in the periphery of forest would involve high transaction costs of establishing institutions on property rights on biodiversity and TKB and mechanisms to distribute. At present in Sri Lanka the natural forests are the property of the state and not of the community or individuals. Hence, the state could appropriate pharmaceutical prospecting values and invest such in the buffer zones of the forest. Sri Lanka has progressed, though slowly, in establishing the required legal framework. A major component of the Medicinal Plant Conservation Project of Sri Lanka is promoting legal and regulatory framework to ensure the protection of intellectual property rights (The World Bank, 1997). Draft legislation on biodiversity property rights too has been prepared. This study strengthens the need to expedite this process.

Downward slopping demand curve: Barrett and Lybbert (2000) claims that although the value of pharmaceutical prospecting estimated by Rausser and Small (2000) are high enough to provide incentives for conservation of some sites, with high biodiversity and prior knowledge of it, given the downward sloping nature of the demand curve, taken over the range of biodiversity sites, the values would not be high enough to conserve biodiversity through pharmaceutical prospecting. As Sri Lanka is placed high on the demand curve, Sri Lanka should expedite formalizing pharmaceutical prospecting, to gain early benefits.

Lack of effective demand: Anon (2002) argues that given the fact that diseases that are common in one society could be uncommon in another, thereby traditional knowledge on use of medicinal 
plants for curative purposes may not be useful. This is particularly true because pharmaceutical companies, being market driven, may be interested in producing drugs for the rich who have the purchasing power and not for the poor (who have TKB). ${ }^{15}$

Single shot extraction: Barret and Lybbert (2000) noted that if companies interested in pharmaceutical companies discontinue their investment in a site once a discovery is made (or even after full search), then it may not sustain the financing of biodiversity conservation of such a site. Hence, the value of pharmaceutical prospecting should include an intertemporal scarcity rent too, considering biodiversity as a nonrenewable resource. This would have to be invested to bring sustainable benefits such that biodiversity is conserved over time.

Experience on pharmaceutical prospecting contracts: Enthusiasm on pharmaceutical prospecting has not been proportional to its implementation. Pharmaceutical prospecting arrangements that have been implemented have not yet shown impressive results. The contract between INBio of Costa
Rica and Merck pharmaceutical company has amounted only to US\$ 1.1 million (Barrett and Lybbert, 2000). Further, Barret and Lybbert (2000) have reported that the Shaman Pharmaceuticals company had realized (by February 1999) lack of profitability in the investment on pharmaceutical prospecting using indigenous knowledge and transferring benefits to indigenous people and therefore have ceased such investments. As reported by Anon. (2002), quoting Macilwain (1998), a survey of companies involved in pharmaceutical prospecting has found that bioprospecting as not rewarding. As the world leader in biotechnology, the United States of America has not ratified the Convention on Biodiversity and, therefore, the expectation of benefit sharing from pharmaceutical prospecting may not be a reality with the United States of America as it is not obliged to do so.

Influence of biotechnology and synthetic products: If biodiversity is to generate values in pharmaceutical prospecting, it must be able to compete with combinatorial chemistry and genetic modification which could substitute the naturally found chemicals price it could realize large revenues. 
or genes. Anon (2002) has argued that although Rausser and Small (2000) have shown that advances in biotechnology will make bioprospecting cost effective, in contrast biotechnological developments will further reduce pharmaceutical prospecting values. Among the reasons given are that synthetic chemicals are nearly always much easier to synthesize in an industrial scale. There are also some who believe that the most important species are already conserved $e x$-situ and therefore in-situ species may not generate much value.

\section{Conclusions}

Empirical evidence suggests that there exists a reasonable potential for pharmaceutical prospecting to generate revenues to conserve forest biodiversity in Sri Lanka. This potential has improved due not only to the availability of high biodiversity but also the high availability of TKB. Based on the forgoing economic analysis it could be recommended that Sri Lanka should attempt to formally appropriate the benefits from pharmaceutical prospecting, dispelling bio-piracy. The process of establishing legislation and institutions on property rights on appropriating and sharing of benefits from biodiversity and pharmaceutical prospecting should be expedited.
Pharmaceutical prospecting is a highly socially and politically sensitive and contentious issue. Hence, broad and transparent public consultation is essential to decide whether Sri Lanka should engage in pharmaceutical prospecting, with whom, how and when etc.

\section{References}

Anonymous (2002). Bio-prospecting: Why is it so Unrewarding? A Paper Submitted to Biological Conservation, http://wwwuser.york.ac.uk/ drfl/biopros pecting.htm

Anonymous (1998). Sri Lanka: Biopirates Patent Traditional Wisdom, http://www.netlink.de/gen

Aylward, B.A. (1993). The Economic Value of Species Information and its Role in Biodiversity Conservation: Case Studies of Costa Rica's National Biodiversity Institute and Pharmaceutical Prospecting, Environmental Economics Center, London.

Balick, M.J. and R. Mendelshon (1992). Assessing the Economic Value of Traditional Medicines from Tropical Rain Forests, 
Conservation Biology, 6:128-130.

Barrett, Christopher B. and T.J. Lybbert (2000). Is Bioprospecting a Viable Strategy for Conserving Tropical Ecosystem? Ecological Economics, 34 (3): 293-300.

Bogahawatte, C. (1999) Forest Policy, Nontimber Forest Products and the Rural Economy in the Wet Zone Forests in Sri Lanka, http://www.eepsea.org/publi cation.

Bulte, E.H. and P. van Soest Daan (2001). Environmental Degradation in Developing Countries: Household and the (reverse) Environmental Kuznets Curve, Journal of Development Economics, 65(Issue 1):225-235.

Central Bank of Sri Lanka (2000). Annual Report. Central Bank of Sri Lanka.

Gunatilake, I.A.U.N (1991). Towards an Era of Environmentally Sustainable and Community Friendly Forestry in Sri Lanka, in Environment and Economic Development Is there an Eco Friendly Path to
Progress? Institute of Fundamental Studies, Kandy, Sri Lanka.

Gunatilake, H.M., D.M.A.H. Senartne, and P. Abeygunawardena (1993). Role of Non-timber Forest Products in the Economy of Peripheral Villages of Knuckles National Wilderness Area of Sri Lanka: A Farming Systems Approach. Economic Botany, 47(3) :275-281.

Gunawardena, J. (2002). Kothala himbutu; Success of Indirect Action, Midweek Mirror, The Island, 03 April.

Inman, W.D. and M.J. Reed (1977). Trinterpenoid Compounds for the Treatment of Diabetes, US Patent 5691386A, 25 November.

Karaluvinne, S.S.D.K. (2001). An Assessment on Economic Value of Pharmaceutical Prospecting and its Role in Biodiversity Conservation: A Case Study on the Knuckles Range of Forest. A Report Submitted as Partial Fulfillment for the Degree in B.Sc (Agriculture), University of Peradeniya, Sri Lanka. 
IUCN (1994). Knuckles

Conservation Management Plan, International Union for Conservation of Nature, Colombo, Sri Lanka.

Kotagama, H.B. (1996). Sustainable Development through Sustainable Use of Biodiversity: Economic Policy Options. In, Regional Seminar on Forests of the Humid Tropics of South East Asia, National MAB Committee and the Natural Resources, Energy and Science Authority, Sri Lanka.

Kotagama, H.B. (1998). Estimates of Environmental Unit Values in Sri Lanka Applicable to Extended Benefit Cost Analysis of Investment Projects, The Postgraduate Institute of Agriculture, University of Peradeniya, Sri Lanka.

Kotagama, H.B. (2002). Financing Environmental

Conservation: a Case Study in Sri Lanka. In, N. Sanderatne and H.M. Gunatilake (eds.) Essays in Development. Felicitation Volume in Honour of Prof. T. Jogaratnam. Sri Lankan
Agricultural Economics Association, Sri Lanka.

Kumar, V. (2000). Systems and National Experiences for Protecting Traditional Knowledge, Innovations and Practices: Sri Lanka, UNCTAD Expert Meeting on Systems and National Experiences for Protecting Traditional Knowledge, Innovations and Practices, Geneva, 30 October - 1 November.

MacArthur, Robert H. and E.O. Wilson (1967). The Theory of Island Biogeography. Princeton University Press.

Macilwain, C. (1998). When Rhetoric Hits Reality in Debate on Bioprospecting, Nature, 392:535-540.

Moore, T.G. (ud) Loss of Species: Greek Tragedy or Routine Occurrence, http://www.stnford.edu/ mo ore/Biodiversity.html.

Pearce, D.W. and D. Moran (1994). The Economic Value of Biodiversity. London: Earthscan Publications Ltd.

Pearce, D.W. and S. Puroshothamon, (1995). The Economic Value 
of Plant Based

Pharmaceutical. In, T.

Swanson, (ed.), Intellectual Property Rights and Biodiversity Conservation, Cambridge.

Principe, P. (1991). Valuing the Biodiversity of Medicinal Plants. In, O. Akerte, V. Heywood, H. Synge (eds.), The Conservation of Medicinal Plants. Cambridge: University Press.

Principe, P. (1989). The Economic Value of Biodiversity among Medicinal Plants, OECD, Paris.

Pushpakumara, D.K.N.G., H.B. Kotagama, B. Marambe, G. Gamage, K.A.I.D. Silva, L.H.P. Gunaratne, and S. Wijesundara (2001). Value Addition to Products of BioProspecting and Benefit Sharing. Paper Presented at the Annual Forestry Symposium of the University of Sri Jayawardenapura, Sri Lanka.

Putterman, D.M. (1996). Model Material Tansfer Agreements for Equitable Biodiversity Prospecting. Journal of
International Environmental Law and Policy, 1:145-173.

Reardon, T. and S. Vosti (1995). Links between Rural Poverty and Environment in Developing Countries: Asset Categories and Investment Poverty. World Development, 23(9):14951506.

Rausser, G.C. (ud). Final Report: Deriving Biodiversity Option Value within a Model of Biotechnology Research and Development, http://es.epa.gov/ncer/final/g rants/95/valaution/rausser82 4707.html

Rausser, G.C. and A.A. Small, (2000). Valuing Research Leads: Bioprospecting and the Conservation of Genetic Resources. Journal of Political Economy, 108(1).

Rausser, G.C. and A.A. Small (1998). Bio-prospecting with Patent Races, PaineWebber Working Paper Series in Money, Economics and Finance. Colombia Business School, Columbia University, http://www.columbia.edu/cu/ business/wp/. 
Shimodo, H., S. Kawamori and Y. Kawahara (1998). Effects of an Aqueous Extracts of Salacia reticulata a Useful Plant in Sri Lanka on Post parandial hyperglycemia in Rats and Humans, Nippon Eiyo, Shokuryo Gakkaishi, 51(5): 279-281 [as reported in Chemical abstracts (1998) 129:335564]

Simpson, D.R., R.A. Sedjo, and J.W.

Reid,

(1996).Valuing

Biodiversity in

Pharmaceutical Research.

Journal of Political

Economy, 104(1):163-185.

Simpson, D.R. and R.A. Sedjo, (1996). Investment in Biodiversity Prospecting and Incentives for Conservation. Discussion Paper 96-14, Resources for the Future, Washington.

Simpson, D.R. (1995). Biodiversity Prospecting and Biodiversity Conservation, htttp://economics.iucn.org

The World Bank (1997). Grant for Conservation of Medicinal Plants in Sri Lanka. Project First of Its Kind for World Bank, Press Release 98/1585SAS, http://www.worldbank.org/ht ml/extdr/extme/1585.htm

Thushantha, L.K.M.N and H.B. Kotagama (1995). The Economic Value of Pharmaceutical Prospecting and its Role in Biodiversity Conservation: A Case Study of Sinharaja Forest. Natural Resources and Environment Policy Project, Sri Lanka.

Vogel, J.H. (1997). The Successful Use of Economic Instruments to Foster Sustainable Use of Biodiversity: Six Case Studies from Latin America and Caribbean; White Paper, Biopolicy Journal, 2, Paper 5, http://www.bdt.org/ bioline/py.

Wijesinghe, L.C.A de S., I.A.U.N. Gunatilake, S.D.G Jayawardena, S.W Kotagama and C.V.S. Gunatilake (1993). Biological Conservation in Sri Lanka. A National Status Report. Revised Version 1993. IUCN, the World Conservation Union, Sri Lanka Country Office, Colombo.

Yamahara, J. (1999). Compound SP from Salacia prinoides as a 
alpha-glucosidase Inhibitor Anti-diabetic. Japanese Patent JP 11029472, February.

Yoshikawa, M., T. Murukami, M.H. Shimada, J. Yamahara, J., G. Tanabe and O. Muraoka (1998a). Salacinol, Potent Antidiabetic Principle with Unique Thiosugar Sulfonium Sulfate from the Ayurvedic Traditional Medicine Salacia reticulata in Sri Lanka and India. Tetrahedron Letters, 38(48) :8367-8370.

Yoshikawa, M., T. Murukami, K. Yashiro and $\mathrm{H}$. Matsuda (1998b). Kotalanol. Potent Alpha-glucosidase Inhibitor with Thiosugar Sulfonium Sulfate from Antidiabetic Ayurvedic Medicine salacia reticulata (1998b) Chemical and Pharmaceutical Bulletin (Japan), 46 (8):1339-1340.

Yoshikawa, M., T. Murukami, K. Yashiro, H. Matsuda, O. Muraoko, G. Tanabe and J. Yamahara J. (1998c). AntiDiabetic Constituents of Sri Lankan Natural Medicines kotal himbutu (Salacia reticulata): Absolute Stereochemistry of AlphaGlucosidase Inhibitors, Salacinol and Kotalanol with Unique Thiosugar Sulfonium Sulfate Inner Salt Structure (1998) Tennan Yuki Kagobutsu Tornkai Koen Yoshishu, 40 ${ }^{\text {th }}, 67-72$, [as reported in Chemical Abstracts (1999) 131: 106694. 